Article

\title{
Framework Phylogeny, Evolution and Complex Diversification of Chinese Oaks
}

\author{
Jia Yang ${ }^{1, * \mathbb{D}}$, Yu-Fan Guo ${ }^{1}$, Xiao-Dan Chen ${ }^{1}$, Xiao Zhang ${ }^{1}$, Miao-Miao Ju ${ }^{1}$, Guo-Qing Bai ${ }^{1,2}$, \\ Zhan-Lin Liu ${ }^{1}$ (D) and Gui-Fang Zhao ${ }^{1, *}$ \\ 1 College of Life Sciences, Northwest University, Xi'an 710069, China; guoyufan@stumail.nwu.edu.cn (Y.-F.G.); \\ chenxiaodan@stumail.nwu.edu.cn (X.-D.C.); zhxiao@nwu.edu.cn (X.Z.); jumm089@nwu.edu.cn (M.-M.J.); \\ bgq@ms.xab.ac.cn (G.-Q.B.); liuzl@nwu.edu.cn (Z.-L.L.) \\ 2 Institute of Botany of Shaanxi Province, Xi'an 710061, China \\ * Correspondence: yjhgxd@stumail.nwu.edu.cn (J.Y.); gfzhao@nwu.edu.cn (G.-F.Z.)
}

Received: 24 July 2020; Accepted: 12 August 2020; Published: 13 August 2020

check for updates

\begin{abstract}
Oaks (Quercus L.) are ideal models to assess patterns of plant diversity. We integrated the sequence data of five chloroplast and two nuclear loci from 50 Chinese oaks to explore the phylogenetic framework, evolution and diversification patterns of the Chinese oak's lineage. The framework phylogeny strongly supports two subgenera Quercus and Cerris comprising four infrageneric sections Quercus, Cerris, Ilex and Cyclobalanopsis for the Chinese oaks. An evolutionary analysis suggests that the two subgenera probably split during the mid-Eocene, followed by intergroup divergence within the subgenus Cerris around the late Eocene. The initial diversification of sections in the subgenus Cerris was dated between the mid-Oligocene and the Oligocene-Miocene boundary, while a rapid species radiation in section Quercus started in the late Miocene. Diversification simulations indicate a potential evolutionary shift on section Quercus, while several phenotypic shifts likely occur among all sections. We found significant negative correlations between rates of the lineage diversification and phenotypic turnover, suggesting a complex interaction between the species evolution and morphological divergence in Chinese oaks. Our infrageneric phylogeny of Chinese oaks accords with the recently proposed classification of the genus Quercus. The results point to tectonic activity and climatic change during the Tertiary as possible drivers of evolution and diversification in the Chinese oak's lineage.
\end{abstract}

Keywords: Quercus; phylogeny; evolution; rapid radiation; morphological divergence

\section{Introduction}

Species diversity is a key element of biodiversity on earth [1,2]. Reconstructing the evolutionary history of species-rich taxa provides fundamental insights about the forces shaping biodiversity [3-5]. Previous research targeting various taxa suggest that complex interactions, including abiotic elements (e.g., geohistorical and climatic fluctuations), biological factors (e.g., random genetic drift, introgression and life-history characteristics of organisms), and stochastic processes, could promote genetic turnover, evolution, and speciation [6-11]. Furthermore, these interactions have been hypothesized to correlate with evolutionary trade-offs in organisms' investment strategies and, as a consequence, they can potentially shape the patterns of the morphological divergence and diversification rates across species evolution [12].

Quercus L. (Fagaceae) exhibits spectacular levels of species richness among angiosperms. Oaks are considered keystone species and they constitute the highest biomass to forest ecosystems in the Northern Hemisphere [13-15]. Central America and Mexico are a center of recent oak diversification, where the diverse oak species are demonstrated to be originated from North American oak clades 
through rapid adaptations and niche transitions [16]. Despite the utmost ecological importance of oak species, their classification has been a challenge that started in the 1800s and still continues today [17]. This challenge has resulted in various classification schemes based on morphology or on molecular data, and can be attributed to the complex evolutionary history of oak species, which is characterized by phenotypic similarity, reticulate evolution, and frequent hybridization [7,10,13,18-22]. Chinese oaks have not been the exception to this problem and have traditionally been classified into two genera or subgenera (Quercus and Cyclobalanopsis) based on phenotypic characters [23-25]. Recent work using genome data has made significant progress in the classification at the infrageneric level of genus Quercus [26]. In the updated classification, genus Quercus is separated into subgenera Quercus and Cerris, which correspond to the New and the Old World oaks, respectively. Subgenus Quercus encompasses five infrageneric sections: the white oaks (section Quercus), red oaks (section Lobatae), intermediate oaks (section Protobalanus), live oaks (section Virentes) and a relictual group with two endemic oak species (section Ponticae). Subgenus Cerris comprises three infrageneric groups, of which sections Ilex and Cerris are exclusively distributed across Eurasia, while section Cyclobalanopsis is entirely found in Asia [26,27]. However, for the Chinese oaks, although the DNA barcoding approach had been adopted to explore infrageneric groups and species boundaries among some Chinese oak species [28,29], to date a phylogenetic test assessing the Chinese oak's lineage based on molecular data is lacking.

China hosts ca. 130 oak species according to Flora of China and is considered the diversity center of Eurasian oak species [23]. Fossil records and recently published molecular research suggest that the evergreen oak species of sections Ilex and Cyclobalanopsis probably originated in Southwestern China [30-32]. In terms of distribution, the Chinese oak species range from the eastern Himalaya to Taiwan Island, and from northeastern China to Hainan Island in subtropical and temperate areas, accounting for a prominent part of woody vegetation in East Asia and thus reflecting a remarkable ecological flexibility [33].

Despite the ecological and evolutionary importance of Chinese oaks, the diversification patterns and evolutionary history of the Chinese oak's lineage are not well estimated. A series of phylogeographic research on some widespread Chinese oak species suggest that geographical distribution and climate change during the past geological periods could have affected the intra- and interspecific genetic variation of these species [34-41]. Additionally, research on Chinese oak species seems to imply that adaptation to different environments may influence genetic diversity, species turnover, and thus be relevant for the implementation of conservation strategies [32,42]. Given that a well-resolved phylogeny could provide a framework to understand diversification patterns and the evolutionary history of plant species [16], it is imperative to generate a framework phylogeny of the Chinese oaks to understand the evolutionary process and diversification pattern of this species-rich group.

The purposes of this study are: (1) to generate a phylogenetic framework and evolutionary history for 50 Chinese oak species (Table 1) based on five chloroplast regions and two nuclear loci, (2) to use simulations to understand the lineage diversification patterns and multiple traits-based evolution of the Chinese oak species under study, and (3) use simulation data to explore the potential association between the lineage diversification and phenotypic evolution in the Chinese oak's lineage. 
Table 1. Taxon information and phenotypic features of the Chinese oak species used in this study.

\begin{tabular}{|c|c|c|c|c|c|c|}
\hline Section & Taxon & Samples & Leaf Character & Cupule Character & Florescence Range & Fruiting Period with Florescence \\
\hline \multirow[t]{12}{*}{ Quercus } & Quercus aliena Blume & 9 & Deciduous & Ovate bract & Apr--May & Present year \\
\hline & Q. aliena var. acutiserrata Maximowicz ex Wenzig & 9 & Deciduous & Ovate bract & Mar.-Apr. & Present year \\
\hline & Q. dentata Thunb. & 9 & Deciduous & Lanceolate bract & Apr.-May & Present year \\
\hline & Q. fabri Hance & 9 & Deciduous & Ovate bract & Apr. & Present year \\
\hline & Q. griffithii Hooker and Thomson ex Miquel & 6 & Deciduous & Ovate bract & Apr.-May & Present year \\
\hline & Q. liaotungensis Koidz. (or Q. wutaishanica Blume) & 9 & Deciduous & Ovate bract & Apr.-May & Present year \\
\hline & Q. mongolica Fischer ex Ledebour & 9 & Deciduous & Ovate bract & Apr.-May & Present year \\
\hline & Q. robur L. ${ }^{\dagger}$ & 2 & Deciduous & Ovate bract & Mar.-Apr. & Present year \\
\hline & Q. serrata Murray & 8 & Deciduous & Ovate bract & Mar.-Apr. & Present year \\
\hline & Q. serrata var. brevipetiolata (A. DC.) Nakai & 6 & Deciduous & Ovate bract & Mar.-Apr. & Present year \\
\hline & Q. stewardii Rehd. & 3 & Deciduous & Lanceolate bract & Mar.-Apr. & Present year \\
\hline & Q. yunnanensis Franchet & 3 & Deciduous & Lanceolate bract & Mar.-Apr. & Present year \\
\hline \multirow[t]{22}{*}{ Ilex } & Q. acrodonta Seemen & 6 & Evergreen & Ovate bract & Mar.-Apr. & Present year \\
\hline & Q. aquifolioides Rehd. and Wils. & 8 & Evergreen & Ovate bract & May-Jun. & Present year \\
\hline & Q. baronii Skan & 9 & Semievergreen & Lanceolate bract & Apr. & Following year \\
\hline & Q. cocciferoides Hand.-Mazz. & 3 & Evergreen & Ovate bract & Apr.-Jun. & Present year \\
\hline & Q. dolicholepis A. Camus & 6 & Evergreen & Lanceolate bract & Mar--May & Following year \\
\hline & Q.engleriana Seemen & 3 & Evergreen & Ovate bract & Apr.-May & Present year \\
\hline & Q. franchetii Skan & 3 & Evergreen & Ovate bract & Feb.-Mar. & Present year \\
\hline & Q. gilliana Rehd. and Wils. & 3 & Evergreen & Ovate bract & May-Jun. & Present year \\
\hline & Q. guyavifolia H. Leveille & 8 & Evergreen & Ovate bract & Apr.-May & Present year \\
\hline & Q. lanata Smith & 3 & Evergreen & Ovate bract & May-Jun. & Following year \\
\hline & Q. longispica (Hand.-Mazz.) A. Camus & 6 & Evergreen & Ovate bract & May-Jun. & Present year \\
\hline & Q. monimotricha Hand.-Mazz. & 4 & Evergreen & Ovate bract & May-Jun. & Following year \\
\hline & Q. oxyphylla (E. H. Wilson) Hand.-Mazz. & 6 & Evergreen & Lanceolate bract & May-Jun. & Following year \\
\hline & Q. pannosa Hand.-Mazz. & 4 & Evergreen & Ovate bract & May-Jun. & Following year \\
\hline & Q. phillyraeoides A. Gray & 6 & Evergreen & Ovate bract & Mar-Apr. & Present year \\
\hline & Q. pseudosemecarpifolia A. Camus & 6 & Evergreen & Ovate bract & May-Jun. & Present year \\
\hline & Q. rehderiana Hand.-Mazz. & 3 & Evergreen & Ovate bract & May-Jun. & Present year \\
\hline & Q. semecarpifolia Smith & 3 & Evergreen & Ovate bract & May-Jun. & Present year \\
\hline & Q. senescens Hand.-Mazz. & 10 & Evergreen & Ovate bract & Mar--May & Present year \\
\hline & Q. spinosa David ex Franchet & 15 & Evergreen & Ovate bract & May-Jun. & Following year \\
\hline & Q. tarokoensis Hayata & 4 & Evergreen & Ovate bract & Apr.-May & Following year \\
\hline & Q. utilis $\mathrm{Hu}$ and W. C. Cheng & 3 & Evergreen & Ovate bract & Apr.-May & Present year \\
\hline
\end{tabular}


Table 1. Cont.

\begin{tabular}{|c|c|c|c|c|c|c|}
\hline Section & Taxon & Samples & Leaf Character & Cupule Character & Florescence Range & Fruiting Period with Florescence \\
\hline \multirow[t]{3}{*}{ Cerris } & Q. acutissima Carruth. & 9 & Deciduous & Subulate bract & Mar-Apr. & Following year \\
\hline & Q. chenii Nakai & 3 & Deciduous & Lanceolate bract & Mar-Apr. & Following year \\
\hline & Q. variabilis Blume & 6 & Deciduous & Subulate bract & Mar-Apr. & Following year \\
\hline \multirow[t]{13}{*}{ Cyclobalanopsis } & Q. arbutifolia Hickel and A. Camus & 2 & Evergreen & Ring shaped bract & Dec.-Jan. & Following year \\
\hline & Q. championii (Bentham) Oersted & 3 & Evergreen & Ring shaped bract & Dec.-Mar. & Following year \\
\hline & Q. gilva (Blume) Oersted & 5 & Evergreen & Ring shaped bract & May & Present year \\
\hline & Q. glauca (Thunberg) Oersted & 7 & Evergreen & Ring shaped bract & Apr.-May & Present year \\
\hline & Q. glaucoides Schottky & 2 & Evergreen & Ring shaped bract & May & Present year \\
\hline & Q. macrocalyx Hickel and A. Camus & 2 & Evergreen & Ring shaped bract & Mar-Apr. & Present year \\
\hline & Q. multinervis W. C. Cheng and T. Hong & 4 & Evergreen & Ring shaped bract & May-Jun. & Following year \\
\hline & Q. myrsinifolia (Blume) Oersted & 7 & Evergreen & Ring shaped bract & Jun. & Present year \\
\hline & Q. neglecta Schottky & 2 & Evergreen & Ring shaped bract & Feb.-Mar. & Following year \\
\hline & Q. oxyodon (Miquel) Oersted & 3 & Evergreen & Ring shaped bract & May-Jun. & Present year \\
\hline & . patelliformis (Chun) Y. C. Hsu and H. W. Jen & 2 & Evergreen & Ring shaped bract & May-Jun. & Present year \\
\hline & Q. sessilifolia (Blume) Schottky & 5 & Evergreen & Ring shaped bract & Apr--May & Present year \\
\hline & Q. sichourensis $\mathrm{Hu}$ & 2 & Evergreen & Ring shaped bract & Apr.-May & Present year \\
\hline
\end{tabular}

Species names in bold indicate monophyletic found on the maximum likelihood phylogeny in Figure 1; phenotypic characters are compiled according to Flora of China; ${ }^{\dagger}$ samples of Quercus robur are collected from cultivation in Tacheng City, Xinjiang Province, China. 


\section{Results}

\subsection{Sequence Information of the Chinese Oaks}

The DNA sequence alignment for the five plastid fragments ranged from 289 (psbA-trnH) to $734 \mathrm{bp}$ (matK) while the two nuclear genes were 332 and $355 \mathrm{bp}$ for the internal transcribed spacer (ITS) and stress-associated protein gene (SAP), respectively (Table S1). All designed primers for the seven loci showed high amplification rates across the 50 Chinese oak species except for one species (Quercus macrocalyx), in which the $p s b \mathrm{~A}-\mathrm{trn \textrm {H }}$ and ITS regions failed to produce results after repetitive PCR sequencing three times. The number of successfully sequenced individuals for the two nuclear loci was smaller than the samples obtained with the five chloroplast primer pairs due to the species-specific characteristics of SAP gene and the removal of potential ITS pseudogenes (Table S1).

The three genetic datasets (plastid dataset, nuclear dataset and combined plastid-nuclear data matrix) contained 239, 205 and 184 sequences, respectively, from 49 oak species for subsequent phylogenetic analyses. The maximum frequency of derived mutations (MFDM) tests among the Chinese oak species suggested no significant deviation from neutral evolution for the seven genetic loci (Table S1). An examination of chloroplast and nuclear data showed that the Chinese oaks have high levels of genetic diversity; similar results were obtained for the identified sections Quercus, Ilex, and Cyclobalanopsis. An exception to this pattern was the chloroplast dataset for section Cerris, which showed moderate genetic diversity; however, the nuclear data for this section also indicated high levels of genetic diversity (Table S2).

\subsection{Infrageneric Phylogeny of the Chinese Oak's Lineage}

Two major clades of the Chinese oak's lineage were identified based on the maximum likelihood and neighbor-net analyses of the three genetic datasets. These two groups correspond to the deep divergence between the New World (subgenus Quercus) and the Old World oak clades (subgenus Cerris) (Figure 1, Figures S1 and S2). The New World oak clade comprised all Chinese white oaks (Quercus section Quercus) with strong bootstrap supports (>95). The rest comprised species from sections Cerris, Ilex and Cyclobalanopsis, clustered within the Old World oak clade. Section Cerris formed a monophyletic group with a strong bootstrap support ( $>90)$; however, it was unexpectedly nested within section Ilex (Figure 1a). Additionally, the later section (in chloroplast-based and chloroplast-nuclear-based phylogeny, Figure 1a and Figure S1) and section Cyclobalanopsis (in nuclear-based phylogeny, Figure S2) were not monophyletic. The best infrageneric framework uses a concatenated plastid-nuclear dataset, particularly the neighbor-net phylogenetic relationship that takes into account conflicting signals between chloroplast and nuclear loci, and clearly recovered the four proposed sections of the Chinese oak species according to the newly updated classification of the genus Quercus (Figure 1b).

Of the 50 Chinese oaks with two or more samples, 13 were found monophyletic on the best maximum likelihood phylogeny. Within sections Ilex and Cyclobalanopsis, the monophyletic oaks are endemic species with narrow distribution ranges (e.g., Quercus cocciferoides, Q. utilis, Q. tarokoensis, Q. arbutifolia and $Q$. sichourensis) or species with samples collected from a single location (e.g., Q. semecarpifolia and Q. gilva). Within section Cerris, the widespread Q. acutissima was monophyletic with a moderate support value (=57), suggesting possible genetic isolation with its sympatric sibling (Q. variabilis). By contrast, individuals of the Chinese white oaks from section Quercus were mixed together and no monophyly of a white oak species was supported by the phylogenetic relationships, indicating unclear species boundaries among these closely related species (Figure 1a; Table 1). 
(a)

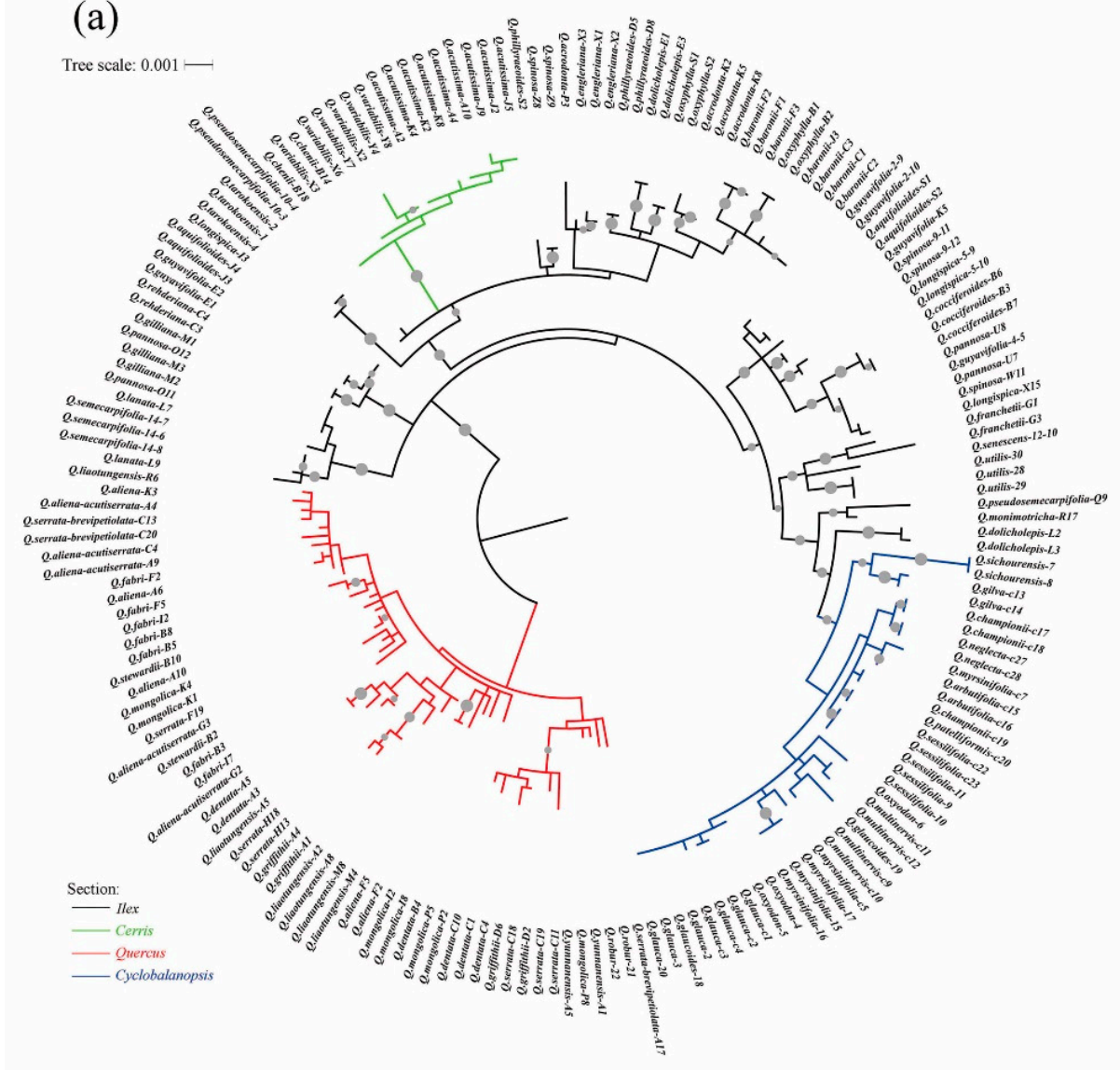

(b)

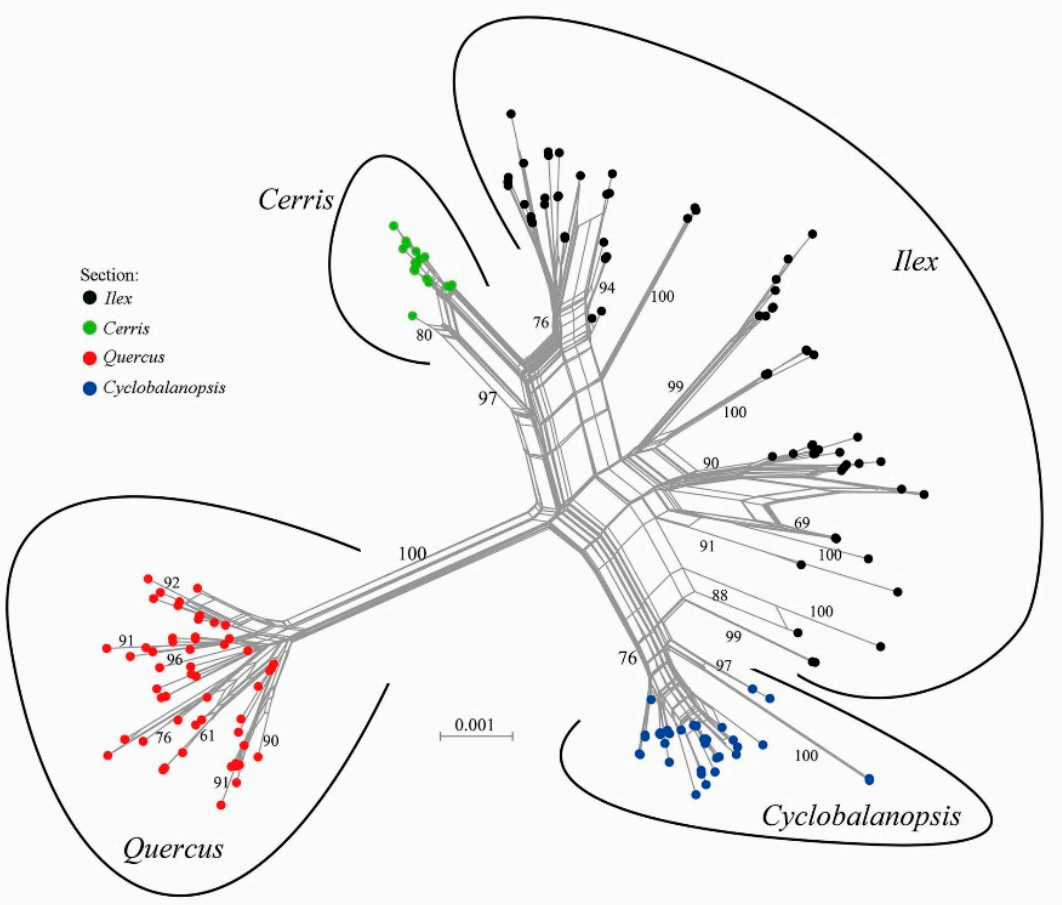

Figure 1. Infrageneric phylogeny of Chinese oak species inferred with (a) maximum likelihood and (b) neighbor-net methods using combined chloroplast-nuclear dataset. The four identified sections in the Chinese oak's lineage are color-coded. Gray circles on branches of the maximum likelihood tree indicate bootstrap values $>60$, and bootstrap confidence $>60$ were showed for major clusters on the neighbor-net network. 


\subsection{Evolutionary History of the Chinese Oaks}

Bayesian evolutionary analyses provided a concordant infrageneric phylogeny for the Chinese oak's lineage at the species level (Figure 2). Based on two fossil-calibrated time points, the evolutionary tree indicated that the divergence between the Quercus ancestor and the outgroup occurred at about 65.54 Ma with a 95\% highest posterior density (95\% HPD) around 46.43-95.56 Ma. The initial divergence between the Old World oak clade and New World oak clade was estimated at $43.54 \mathrm{Ma}$ (95\% HPD: 25.02-64.92 Ma) (node A in Figure 2; Table 2). Within the Old World oak clade, the first split (node B) happened between the ring-cupped oak clade (section Cyclobalanopsis) and the Ilex-Cerris cluster at about 38.69 Ma with a moderate posterior probability ( $\mathrm{PP}=0.58$ ); this event was closely followed by the divergence between sections Ilex and Cerris around 36.04 Ma (95\% HPD: 28.37-52 Ma, node C). The crown ages of sections Cyclobalanopsis (node D) and Ilex (node E) were close to 29.29-30.97 Ma, while the Cerris crown age (node F) was estimated to be $24.56 \mathrm{Ma}$ (95\% HPD: 18.47-30.44 Ma). For the white oak clade (section Quercus), the lineage diversification of this group (node G) was inferred at about 6.66 Ma with a 95\% HPD: 2.61-15.91 Ma (Figure 2; Table 2).

Table 2. Estimations of the major clade age with related abiotic events and mean lineage diversification rates for the Chinese oak's lineage.

\begin{tabular}{|c|c|c|c|c|}
\hline Infrageneric Event & Description (Node) & Time Estimation (Ma) & $\begin{array}{c}\text { Mean } \\
\text { Speciation/Extinction/Turnover } \\
\text { Rate (Species/Myr) }\end{array}$ & $\begin{array}{c}\text { Related } \\
\text { Climatic/Geological } \\
\text { Event }^{+}\end{array}$ \\
\hline \multirow[t]{3}{*}{ Clade divergence } & $\begin{array}{l}\text { New World clade-Old } \\
\text { World clade (A) }\end{array}$ & $\begin{array}{l}43.54 \text { (95\% HPD: } \\
25.02-64.92)\end{array}$ & - & $\begin{array}{c}\text { Early uplift of the } \\
\text { Qinghai-Tibetan Plateau }\end{array}$ \\
\hline & $\begin{array}{l}\text { Cyclobalanopsis- } \\
(\text { Ilex }+ \text { Cerris })(\mathrm{B})\end{array}$ & 38.69 & - & $\begin{array}{l}\text { Eocene-Oligocene } \\
\text { Glaciation }\end{array}$ \\
\hline & Ilex-Cerris (C) & $\begin{array}{c}36.04 \text { (95\% HPD: } \\
28.37-52.00)\end{array}$ & - & $\begin{array}{l}\text { Eocene-Oligocene } \\
\text { Glaciation }\end{array}$ \\
\hline \multirow[t]{4}{*}{ Section diversification } & Cyclobalanopsis (D) & $\begin{array}{c}29.29 \text { (95\% HPD: } \\
15.56-46.97)\end{array}$ & $0.1899 / 0.0934 / 0.2833$ & Oligocene Glaciation \\
\hline & $\operatorname{Ilex}(\mathrm{E})$ & 30.97 & $0.1759 / 0.0865 / 0.2624$ & Oligocene Glaciation \\
\hline & Cerris (F) & $\begin{array}{l}24.56 \text { (95\% HPD: } \\
18.47-30.44)\end{array}$ & $0.1730 / 0.0874 / 0.2604$ & $\begin{array}{c}\text { Late Oligocene } \\
\text { Warming/Establishment } \\
\text { of Asian Monsoon }\end{array}$ \\
\hline & Quercus (G) & $\begin{array}{c}6.66 \text { (95\% HPD: } \\
2.61-15.91)\end{array}$ & $0.2496 / 0.1508 / 0.4004$ & $\begin{array}{c}\text { Miocene } \\
\text { cooling/Intensification of } \\
\text { Asian Monsoon }\end{array}$ \\
\hline
\end{tabular}

HPD: highest posterior density; ${ }^{\dagger}$ related abiotic events are derived from Zachos et al. (2001) and Favre et al. (2015) [43,44].

\subsection{Lineage Diversification and Phenotypic Evolution of the Chinese Oak Species}

Diversification simulations showed varying speciation rates for the phylogeny of the 46 Chinese oak species studied. The phylorate tree suggested only one evolutionary shift (Bayesian factor $=0.21$ ) with an increased speciation rate (mean: 0.2496 species/Myr) on the stem of the Chinese white oaks (section Quercus). Within the Old World oak clade, the ring-cupped oaks from section Cyclobalanopsis showed a slightly higher speciation rate (mean: 0.1899 species/Myr) compared with oaks from sections Ilex (mean: 0.1759 species/Myr) and Cerris (mean: 0.1730 species/Myr) (Figure 3; Table 2). Analyses of terminal diversification rates, including the mean speciation rate (lambda), extinction rate $(\mathrm{mu})$ and turnover rate (lambda $+\mathrm{mu}$ ), indicated that the diversification rate of the Chinese white oak clade was significantly higher than the Old World oak clade, while sections Ilex and Cerris had similar diversification rates (Figure 3; Table 2). Pairwise comparisons of mean speciation rates (lambda rate) among the four identified sections showed significant differences between the New World oak clade (section Quercus) and sections Cerris, Ilex and Cyclobalanopsis, which was confirmed with a Bonferroni $t$-test with 5000 random samples. Similarly, within the Old World oak clade, significant speciation rate differences were found between sections Cerris and Cyclobalanopsis and sections Ilex and Cyclobalanopsis; however, no differences in the simulated speciation rates were found between sections Cerris and Ilex (Table S3). 
(a)

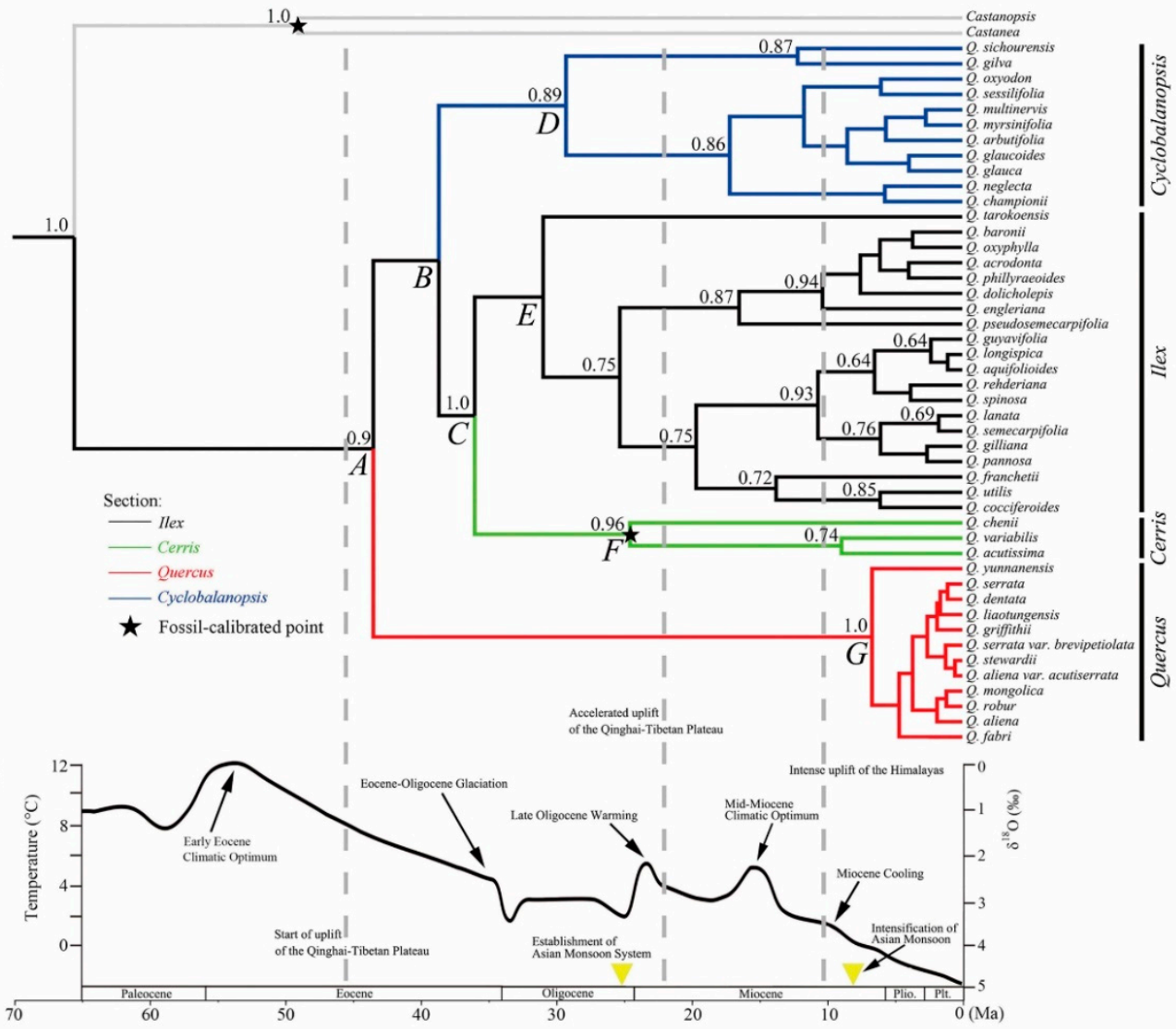

Figure 2. (a) Fossil-calibrated evolutionary history of the Chinese oaks and (b) geohistorical and climate events that possibly impacted on evolution of the Chinese oak's lineage during the Cenozoic era $[43,44]$. Branches of the Bayesian evolutionary tree are colored according to the four identified sections. Black stars indicate fossil-calibrated points used in molecular dating. Posterior probabilities with values $>0.60$ are shown near the nodes. Black curve in (b) indicates the global trends of temperature and average oxygen isotope from Paleocene to Pleistocene. Gray dashed lines and yellow triangles mirror the proposed dynamics of the Qinghai-Tibetan Plateau (QTP)-Himalaya and Asian monsoon systems, respectively.

Simulations of global phenotypic diversification on PC1 traits indicated seven trait-based shifts with probabilities ranging from $<0.02$ to 0.21 across the Chinese oak's lineage (Figure 4). Major transitions of phenotypic traits with high probability were found within the Old World oak clade, and generally corresponded to species clusters with increased phenotypic diversification rates (beta rates). In contrast to the lineage diversification results (Figure 3), the Chinese white oaks (section Quercus) showed relatively low beta rates; also, two shifts with low Bayesian probabilities $(<0.02)$ were identified on the stem of this section and on the endemic Q. stewardii (Figure 4). A Bonferroni $t$-test for pairwise comparison of mean rates in phenotypic evolution (beta rate) among the four identified Chinese oak sections indicated no significant differences between the two deciduous sections Quercus and Cerris. In contrast, the evergreen sections Ilex and Cyclobalanopsis showed significant differences against the deciduous sections Quercus and Cerris in phenotypic evolution. A significant difference in beta rates was also found between sections Ilex and Cyclobalanopsis (Table S3). 


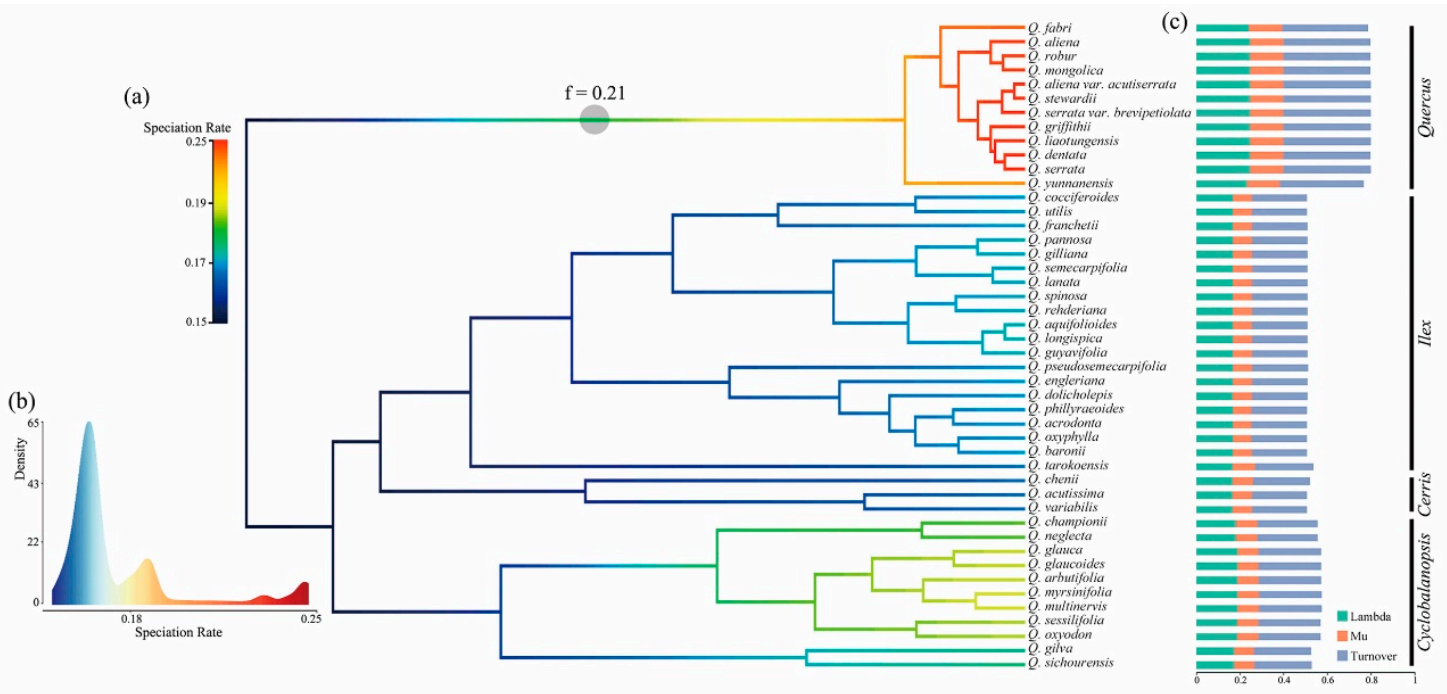

Figure 3. (a) Simulation on the lineage diversification of the Chinese oaks reveals varying diversification rates among the Chinese oak species and an evolutionary shift (Bayesian factor $=0.21$ ) denoted by a gray circle on section Quercus clade. (b) Histogram distribution shows the variant density of speciation rates in Chinese oaks. (c) Bar charts of tip rates (lambda, mu and turnover rates) of lineage diversification for the Chinese oak species on the phylorate tree.

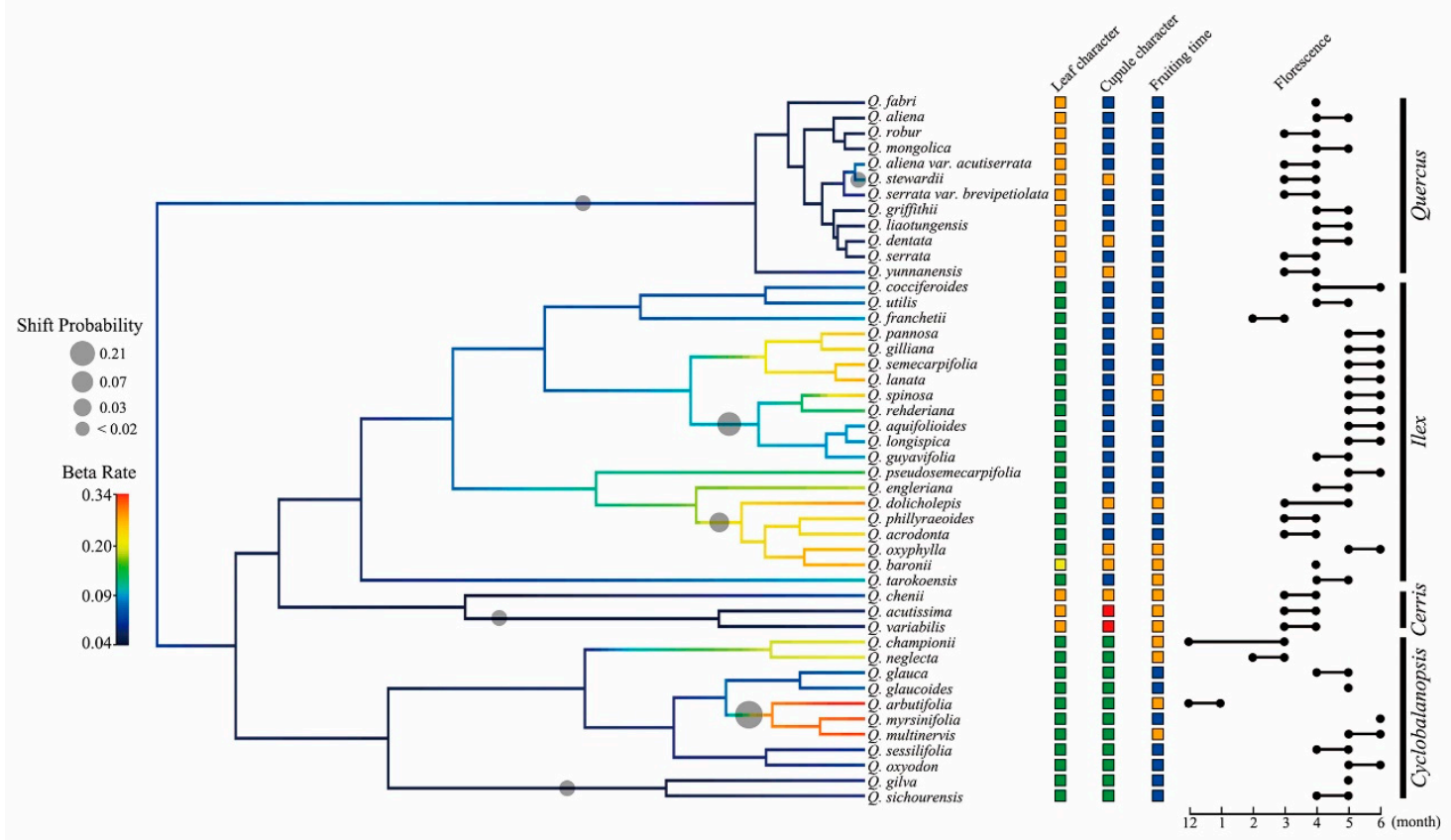

Figure 4. Simulation of the phenotypic evolution of the Chinese oaks suggests heterogeneous rates in trait-based evolution and several phenotypic transitions in the Chinese oak's lineage. Gray circles on branches denote potential phenotypic shifts with varying Bayesian probabilities. Trait characteristics of the tip species are coded with colored squares as follows: leaf character-deciduous (orange), evergreen (green) and semievergreen (yellow); cupule character-ovate bract (blue), lanceolate bract (orange), subulate bract (red) and ring shaped bract (green); fruiting time-present year (blue) and the following year (orange). Dumbbell charts demonstrate the florescent periods of the tip species on the phylogeny.

After using generalized linear regressions, the association analyses suggested significant and negative correlations between the tip rates in the phenotypic divergence and lineage diversification 
(lambda vs. beta: $R^{2}=0.2096, P=0.0014$; mu vs. beta: $R^{2}=0.2522, P=0.0004$ ) for the 46 Chinese oak species in diversification simulations (Figure 5).

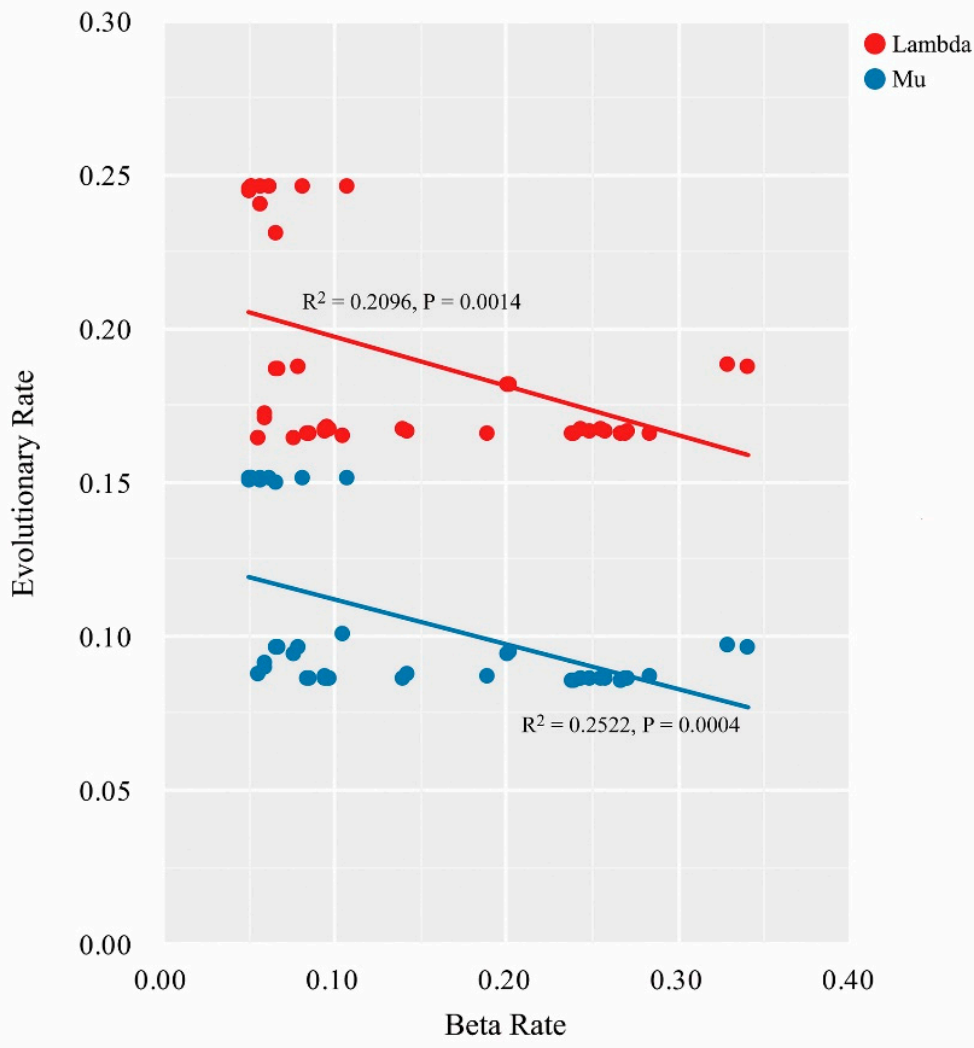

Figure 5. Relationships between the tip rates in the phenotypic evolution (beta rates) and lineage diversification (lambda and mu rates) of the Chinese oak's lineage under a generalized linear regression.

\section{Discussion}

The Chinese oak's lineage is characterized by a high species richness and diverse species morphology, which are proposed as potential origins of oak species diversity $[23,30]$. Despite this, there is no current molecular-based phylogenetic framework to understand the evolution of the Chinese oaks; one of the main reasons for this outcome is, in part, that previous research has focused on oak species from areas outside China. In this study, we integrated chloroplast and nuclear data from 50 Chinese oak species to investigate their phylogenetic relationships, evolutionary history and diversification patterns. Our results provide an infrageneric phylogeny for the Chinese oaks and point to the potential impact of past geological and climatic changes on the evolution and diversification of this species-rich lineage.

\subsection{Infrageneric Phylogeny of Chinese Oaks}

The phylogenetic reconstruction obtained in this study identified two major clades (subgenera Cerris and Quercus) with four sections-Quercus, Ilex, Cerris and Cyclobalanopsis-for the Chinese oak's lineage (Figures 1 and 2). Although a previous study based on chloroplast loci did not provide enough support for these sections [29], the use of a combined plastid-nuclear dataset improved the infrageneric resolution of the Chinese oak phylogeny. An examination of the phylogenetic trees based on separate plastid and nuclear datasets revealed a phylogenetic incongruence, which has previously been documented for oaks $[45,46]$. Specifically, the concatenated chloroplast dataset showed sections Cerris and Cyclobalanopsis as monophyletic but nested within section Ilex, while the phylogenetic tree based on nuclear data revealed a very different tree structure with a monophyletic section Cerris and a polyphyletic section Cyclobalanopsis, both nested within section Ilex (Figures S1 and S2). Apart from 
the limited genetic data used in this study, this incongruence is proposed to be affected by taxonomic decoupling and geographic restraint in the plastid genealogy of oak species; thus, the plastid sequence data is suggested to be less useful for estimating species phylogenetic relationships in oaks $[27,46]$. However, the conflict between the two datasets seems to be recovered by the neighbor-net method in this study, as the neighbor-net network based on combined plastid-nuclear data strongly shows the presence of two subgenera and four infrageneric species groups for the Chinese oak's lineage (Figure 1b). Overall, our results are consistent with the Quercus infrageneric phylogeny proposed by Denk et al. (2017), which is based on a large number of DNA sequences from a comprehensive sampling of European and American oaks [20,21,27,47,48]; furthermore, this updated infrageneric phylogeny is fully consistent with an oak genomic landscape analysis [26].

The infrageneric phylogeny of the Chinese oaks that we obtained shows that only 13 from the 50 collected species were monophyletic, reflecting an extensive introgression and consequent difficulty in defining species boundaries, especially among closely related species. Most of the monophyletic species are endemic in sections Ilex and Cyclobalanopsis; in contrast, not a single monophyletic species was resolved in section Quercus (subgenus Quercus) (Figure 1). These results are likely the consequence of the complex gene flow among closely related species which suggests an incomplete lineage isolation [28,34]. Similar interspecific gene flow patterns have been observed among some close relatives of sections Ilex and Cyclobalanopsis $[49,50]$. Moreover, it is likely that the limited genetic data used in this study is not enough to identify the biological boundaries and phylogenetic relationships among closely related species; thus, additional data will be necessary to identify monophyletic groups. Ideally, the species delimitation problem in oaks could be solved using genome information; however, recent studies based on plastome and genomic data have revealed similar difficulties to those faced in this study. Indeed, several authors have highlighted that, even with the use of genome data, finding monophyletic groups for some oak species is challenging $[26,46]$.

\subsection{Evolutionary History of the Chinese Oaks}

Several research groups have studied the evolutionary history of Quercus and have estimated dissimilar divergence times for different oak groups, e.g., [16,48,51,52]. Based on a robust phylogeny of the genus Quercus, Hipp et al. (2020) obtained older crown times, for all infrageneric clades, than previously reported [26]. In evolutionary analyses, different factors could cause discrepancies in the estimation of molecular dating such as: the calibration time points (e.g., fossil-calibrated point on a crown age or a stem age), the phylogenetic signals among different genetic datasets (e.g., multiple genetic datasets considered in this study), and the inclusion of species from different lineages [16,45,48,51]. In fact, in our study, the limited genetic data and calibrated points could have introduced some bias to the molecular dating. For example, the minimum and maximum age range for section divergence and lineage diversification were broad for some clades (Figure 2; Table 2); these broad age range intervals could be the result of conflicts between the phylogenetic signals from the plastid and nuclear datasets. Despite this situation, the combined chloroplast and nuclear dataset using a coalescent method produced a phylogenetic framework that is consistent with the most recent phylogeny for the genus Quercus (Figure 1).

Our results indicate that the initial divergence of the Chinese oak's lineage, that is the split between the two subgenera Quercus and Cerris, possibly happened around the mid-Eocene, $43.54 \mathrm{Ma}$ (node A in Figure 2; Table 2) when the Qinghai-Tibetan Plateau (QTP) began to uplift $[43,53]$. Contrasting opinions also suggest that the elevation of the QTP reached about $4000-5000 \mathrm{~m}$ at the mid-Eocene epoch (ca. $45 \mathrm{Ma}$ ) [54]. This might have caused a decrease in temperature during mid- to late Eocene, leading to the Eocene-Oligocene glaciation [43,44]. Climatic and geological fluctuations during this period likely caused ecological differentiation between low and high latitude regions, triggering the divergence between ancestors of the Old World oak clade (subgenus Cerris) (from a mid- to low latitude), and the New World oak clade (subgenus Quercus), distributed at a high latitude [27,45]. Within the Old World oak clade, the sections recognized in our work could have arisen before the late Eocene, thus it is possible that the low temperature with an arid environment during the Eocene-Oligocene glaciation could have promoted the 
split of the humidity-adapted Cyclobalanopsis lineage (node B) and the arid-tolerant oaks from section Ilex (node C). Evidence for this inference is the appearance of fossil records of sections Ilex and Cyclobalanopsis in Asia from the mid- to late Eocene [23,55]. According to our reconstruction, the initial diversification within the two evergreen clades (sections Cyclobalanopsis and Ilex, nodes D and E in Figure 2; Table 2) probably took place during the early to mid-Oligocene; during this glacial period, the relatively stable climates likely promoted long distance migration (such as the European holly oaks, which originated from the East Asian oak lineage and migrated via the Tibet-Himalaya corridor) [32] and the geographical isolation of some evergreen oaks (e.g., Q. sichourensis and Q. tarokoensis in this study). We estimated that most species from sections Ilex and Cyclobalanopsis differentiated around the early to mid-Miocene when the intense uplift of the QTP and Himalaya took place; during this time, temperature fluctuations from the climatic optimum to cooler temperatures could have promoted the increase in genetic variation and ecological differentiation of species in these two sections [31,43]. Furthermore, fossil evidence from the Miocene consisting of abundant and morphologically diverse evergreen oak species supports the diversification of sections Cyclobalanopsis and Ilex during this time period in Asia [23]. Within section Cerris, the presence of fossil records in Western Eurasia appears to support our estimation that the first divergence of this group probably happened around the Oligocene-Miocene boundary (node F in Figure 2; Table 2). However, a revised fossil record of section Cerris in the Russian Far East suggests that the differentiation of this section could have occurred in the early Oligocene [56]. If the divergence of Cerris oaks took place during the late Oligocene, then it is possible that the establishment of the Asian monsoon system, with increasing temperatures, might have triggered the differentiation of deciduous oaks in this section. Independently of the origin, the Cerris oaks are currently the most diverse group in Western Eurasia with eight accepted species. In contrast to the early divergence between the New and Old World oak clades, species differentiation within section Quercus likely took place in the late Miocene (node $G$ in Figure 2; Table 2). Species diversification in this section could be the result of descending temperatures and an intensification of the Asian monsoon system during the late Miocene [43]. Within section Quercus, it has been suggested that the Eurasian Roburoid oaks became established around the mid-Miocene period from ancestors of the North American Prinoideae and Albae clades, and then split into East Asian and Western Eurasian lineages since ca. $10 \mathrm{Ma}$ [26], corresponding closely to our time estimation. Similar to previous research on American and Eurasian oak species [16,48], our analyses also support a rapid radiation of the Chinese white oak clade (section Quercus) from the late Tertiary to early Quaternary (Figure 2).

\subsection{Complex Diversification of the Chinese Oak's Lineage}

In general, diversification simulations suggest homogeneous lineage diversification rates (mean lambda: 0.1731 species/Myr) for the 46 oak species studied, with the exception of a possible evolutionary shift (non-core shift) for the Chinese white oak clade (section Quercus) (mean lambda: 0.2496 species/Myr) (Figure 3; Table 2). In a study of global oak evolution based on genomic data, Hipp et al. (2020) found a similar pattern for species in section Quercus; their results showed an evolutionary shift with an increased speciation rate for a group of white oak species referred to as the Roburoid clade (which included some Chinese white oak species) [26]. This evolutionary shift in section Quercus could be the result of different evolutionary dynamics between the New and Old World oak clades, as fossil evidence suggests that the ancestors of these two clades originated in the Nearctic and Palearctic Indomalayan regions, respectively [27,45]; thus, it is possible that species in these clades adapted to the different geological and ecological conditions associated with their distinct regions of origin. Furthermore, different species diversification patterns and migration routes could have led to disparate evolutionary conditions for species in sections Quercus (the New World oak clade) and other sections (the Old World oak clade) [16,26]. Another plausible explanation for the diversification differences between subgenera Quercus and Cerris is that the rapid radiation of the white oak clade since the late Miocene (Figure 2) might generate a conserved evolutionary configuration during relatively short speciation processes [57]. Within subgenus Cerris, the mean diversification rate for the ring-cupped oak clade (section Cyclobalanopsis) is slightly higher than sections Ilex and Cerris 
(Table 2), but it is not identified as a shift by the Bayesian models. Given the small fraction of species from section Cyclobalanopsis included in the Bayesian analysis of macroevolutionary mixtures (BAMM) (Table S4), this result requires further investigation with a more comprehensive sampling.

Simulations on global phenotypic evolution (PC1) suggest a low morphological diversification rate in section Quercus, mirroring the similarity of the morphologies among Chinese white oaks; however, this outcome could be a reflection of the limited phenotypic difference information provided by the selected morphological characters (Figure 4; Table 1 and Table S5). Alternatively, the low morphological diversification rate in section Quercus could be the result of their recent origin (Figure 2) and associated absence of strong reproductive isolation barriers, which could facilitate extensive hybridization. An example that supports the latter statement comes from studies in Roburoid oaks (a subgroup that belongs to section Quercus), such as Q. robur and Q. petraea, which appear to have frequent interspecific introgressions [58]. The taxonomic confusion in the Roburoid clade is proposed to be the result of morphological convergence and niche conservatism [26]. By contrast, Chinese oak sections belonging to the Old World oak clade show diverse rates in phenotypic diversification; possible shifts of morphological traits found on several clusters in sections Ilex and Cyclobalanopsis correspond to the differences in traits of phenotypic characters, florescence and fruiting time (Figure 4; Table 1 and Table S5). Given the early divergence of the Old World oak clade (Figure 2; Table 2), potential reasons for a phenotypic turnover within this clade are its long evolutionary history, adaptation to heterogeneous environments, and divergence caused by migration and geographic disruptions [31,32,45].

Interestingly, the significant and negative linear relationships between the tip rates in the lineage diversification and phenotypic evolution of the Chinese oak's lineage indicate that morphological traits tend to be more differentiated in oak species that have low diversification rates (Figure 5). Complex associations between morphological divergence and species diversification have been predicted in animals [59]. Although this process has rarely been investigated in plant groups, an early study on the species-rich clades Adoxaceae and Valerianaceae has revealed negligible correlations between the rates of diversification and morphological innovation [60]. For the Chinese oaks in this study, it is plausible that the increased rates of lineage diversification in section Quercus (Figure 3; Table 2) could be associated with a relatively high genetic variation (Table S2) in the genome (such as structural variation) [61], while this type of generic variation is not correlated with distinct morphology. Additionally, frequent introgressions among oak siblings likely induces the exchange of adaptive genes as well as reduces the phenotypic variability in section Quercus [58,62]. On the other hand, a study on the diversification patterns of the American oaks in a community assembly showed that the ecological divergence among closely related species from the same clade, accompanied by the niche convergence of species between distant clades, could trigger complex diversification patterns in oak lineages [57]. A third possibility for the negative correlations we found is that the intrinsic trade-offs between the functional traits and phenotypic traits in species investment strategies could generate multivariate associations with lineage diversifications [12,63]. According to this hypothesis, our negative correlations might be a predictor of the diversification process of the Chinese oak's lineage. Yet, given the neutrality of the genetic data in this study (Table S1), future work integrating adaptation genes, functional traits, as well as ecological data may help us understand the complex associations of diversification patterns in the genus Quercus [64].

\section{Material and Methods}

\subsection{Species Information and DNA Extraction}

We collected 268 individuals representing 50 Chinese oak species covering the proposed infrageneric groups of Eurasian oaks. Species identifications were made based on their morphological descriptions in Flora of China (Table 1). Oak samples were collected from natural populations and arranged according to the identified taxonomy of the genus Quercus [26,27]. Of the 50 oaks studied, Quercus robur is a European oak species and was sampled from cultivation in Tacheng City, Xinjiang Province. Voucher specimens of the collected oak species were archived in the herbarium of the College of Life Sciences at Northwest University. 
Fresh leaves were collected from adult oak trees and were dried with silica gel prior to DNA extraction. The total genomic DNA was isolated using the plant genomic DNA Kit from TIANGEN (Tiangen, Beijing, China) and stored at $4{ }^{\circ} \mathrm{C}$ for PCR amplification.

\subsection{PCR Amplification and Molecular Data Processing}

Five chloroplast DNA fragments ( $p s b \mathrm{~A}-\operatorname{tr} n \mathrm{H}, m a t \mathrm{~K}, y c f 1, y c f 3-t r n \mathrm{~S}$ and $m a t \mathrm{~K}-\operatorname{tr} n \mathrm{~K})$, showing relatively high genetic variations in some Chinese oaks, were selected from the preliminary research [28]. Two nuclear regions, the internal transcribed spacer (ITS, partial regions) and a confirmed single-copy gene SAP (a predicted stress-associated protein gene) [28] were also sequenced for all samples collected. The primer information for these seven loci is listed in Table S1. PCR amplifications were performed in a PTC-2000 thermal cycler (MJ Research) following Yang et al's method [65], and the PCR products were purified and sequenced by Sangon (Sangon Biotech, Shanghai, China). All obtained sequences for this study were deposited in GenBank with accession numbers: KX836866-KX838287, MT129797-MT130099, and MT131185-MT131230.

All DNA sequences obtained were checked and aligned in BioEdit 7.0.9.0 [66]. Ambiguous sites with poly-(A/T) structures detected in three plastid fragments ( $p s b \mathrm{~A}-\operatorname{trn} \mathrm{H}, y c f 3-t r n \mathrm{~S}$ and matK-trnK) and poly-C in the ITS region were deleted from the alignments. Insertion-deletions (indels) were treated as missing data and removed prior to the analyses. Following the criteria used by Yang et al. (2017), the obtained sequences of the ITS region were carefully examined to filter out potential pseudogenes, while functional ITS orthologues were retained for phylogenetic reconstruction [28]. Sequencing peaks of nucleotide sites with an overlap greater than $80 \%$ in the two nuclear loci were treated as heterozygous, and the ambiguity code was used to replace the overlapped sites according to the IUPAC (International Union of Pure and Applied Chemistry). For each alignment of plastid and nuclear data, a neutrality test using the maximum frequency of derived mutations (MFDM) method, with a 5\% significance level, was performed to detect selection among the Chinese oak samples [67].

\subsection{Reconstruction of Infrageneric Phylogeny}

The individual alignments of the seven genetic regions provided poor information for deciphering the Chinese oaks infrageneric phylogeny (Figures S3 and S4); thus, the aligned genetic data were processed as three data matrices: (1) the concatenated chloroplast data matrix, (2) concatenated nuclear dataset, and (3) combined chloroplast-nuclear genetic data for phylogenetic tests. For the chloroplast (matrix 1) and nuclear (matrix 2) datasets, the global indices of genetic diversity (such as polymorphic and parsimony sites, gene and nucleotide diversity, and variance of segregating sites) for the Chinese oak's lineage and each identified section were estimated using DnaSP 5.0 [68].

The ultrafast bootstrap approximation (UFBoot) implemented in the IQ-TREE software package was used to estimate the maximum likelihood (ML) phylogeny for the Chinese oak species under study $[69,70]$. Unrooted ML trees were constructed for the three genetic data matrices and for the individual gene alignments. The evolutionary models were initially evaluated by Bayesian schemes with the ModelFinder option and Akaike information criterion (AIC) implemented in the IQ-TREE for the three datasets. Phylogenetic trees were then estimated using the best-fit partition models with 1000 UFBoot replicates. Final trees were visualized in iTOL v4 [71].

The neighbor-net method was also used to estimate the genetic relationships among all oak samples in SplitsTree4 [72]. This method is an extension of the neighbor-joining method and quantifies the potential conflicting signals among multiple genetic loci for phylogenetic analyses. For heterozygous sites, all possible resolutions were averaged using the uncorrected P-distance, and 1000 bootstrap simulations were estimated for the neighbor-net network.

\subsection{Molecular Dating}

To estimate the evolutionary history of the Chinese oak species, we utilized a multispecies coalescent-based Bayesian analysis, as implemented in BEAST 1.8.4 [73], for the combined chloroplast-nuclear 
data matrix (matrix 3). Species samples from Castanopsis and Castanea were included as outgroups. The combined chloroplast-nuclear data matrix was partitioned into six input groups $(p s b \mathrm{~A}-t r n \mathrm{H}$, matK, $y c f 1, y c f 3-t r n S+m a t \mathrm{~K}-\operatorname{trnK}$, ITS, SAP) according to the IQ-TREE partition results (Table S1), and their corresponding evolutionary models were used to estimate the Bayesian evolutionary tree. For the data matrix, 46 of the 50 Chinese oak species with more than two individuals were retained, and a "trait" file was compiled to assign the samples of each oak species. The Bayesian evolutionary tree was calculated using a relaxed clock model in a lognormal distribution and a linear coalescent species model with a birth-death speciation process. Heterozygous sites in the two nuclear regions were treated as polymorphisms with a modified setting ("useAmbiguities" = "true") in the input file for estimation. Three independent runs were carried out with $8 \times 10^{8}$ Markov chain Monte Carlo $(\mathrm{MCMC})$ generations and sampled every $10^{4}$ generations to ensure an effective sample size (ESS $>200$ ) and model convergence. We considered two fossil time points to calibrate the divergence of major groups among the Chinese oaks: (1) a normal divergence between genera Castanopsis and Castanea at a mean age of 45-55 Ma [74], and (2) a minimum split time at $23 \mathrm{Ma}$ for the crown age of section Cerris (23-33 Ma) [48]. The final results of the three independent simulations were combined using LogCombiner, and a maximum clade credibility (MCC) tree with a posterior probability $>0.8$ was calculated after removing the first $20 \%$ simulations as burn-in. The fossil-calibrated MCC tree of the Chinese oak's lineage was visualized in FigTree 1.4.2 from the BEAST software package. Major climatic and geological events during the Cenozoic era were derived to evaluate the possible abiotic triggers of divergence and diversification for the Chinese oak's lineage $[43,44]$.

\subsection{Diversification Simulation}

Based on the Bayesian evolutionary tree for the Chinese oak species, we simulated the patterns of lineage diversification by estimating the transitions of diversification rates using the time-varying speciation-extinction model in the Bayesian analysis of macroevolutionary mixtures (BAMM) program [75]. To account for our incomplete species sampling of Chinese oaks, a species-specific file indicating sampling fractions of the backbone (Table S4) was compiled to correct for a possible analytical bias during the simulations of lineage diversification. The R package "BAMMtools" was used to configure the prior parameters and downstream analyses of BAMM simulations [76]. The analyses were performed with $10^{7} \mathrm{MCMC}$ generations and sampled every 1000 swap periods across four Markov chains for convergence.

The phenotypic diversification of the Chinese oak species was also evaluated using the trait-based model in the BAMM program. We assembled four species-specific traits including the leaf character, cupule character, mid-time of florescence and fruiting for the collected Chinese oak species (Table 1) based on the morphological descriptions in Flora of China. The four phenotypic traits represented in a numerical format were processed using a principal component analysis (PCA) (Figure S5), and the standard scores for each oak species on the first principal component (PC1, accounted for $51.6 \%$ of the variance in the PCA) (Table S5) were extracted and used to simulate the global traits-based diversification of the Chinese oak species using BAMM. Simulations were performed with $8 \times 10^{8} \mathrm{MCMC}$ generations and sampled every 4000 generations under four Markov chains.

For the identified infrageneric sections on the Chinese oaks phylogeny, a pairwise comparison of diversification rates from BAMM simulations was estimated using a Bonferroni $t$-test with 5000 random samples of each infrageneric section. The potential associations between the tip rates in the lineage diversification and phenotypic evolution of the Chinese oaks were assessed with a generalized linear regression. These statistical analyses were performed in R 3.6 [77].

\section{Conclusions}

In this study, we generated a framework phylogeny for 50 Chinese oak species based on chloroplast and nuclear data. Our infrageneric framework clearly identifies two subgenera (Quercus and Cerris) and four infrageneric sections (Quercus, Cerris, Ilex and Cyclobalanopsis), in agreement with the most recent 
phylogeny of the genus Quercus [27]. Additionally, the results support that the widely used traditional classification of Chinese oak species based on morphology needs to be revised. In terms of evolutionary history, our study suggests that the primary divergence of the Chinese oaks probably occurred at mid-Eocene, and was followed by the establishment of sections Cerris, Ilex, and Cyclobalanopsis in subgenus Cerris around the late Eocene to early Oligocene. Furthermore, we estimated that the rapid diversification of the Chinese white oaks from section Quercus probably began since the late Miocene. Using a temporal simulation model on diversification patterns, we found a potential evolutionary shift on the Chinese white oak clade, suggesting an evolutionary decoupling between the New World and Old World oaks at their initial divergence. Additionally, we identified several phenotypic shifts for all sections in the Chinese oak's lineage, which suggests a complex history of diversification during the evolution of oak species. Given the ecological importance of the genus Quercus, this research provides evidence that integration of abiotic processes, including tectonic activity and climatic fluctuations during the Tertiary, have shaped the evolution and diversification of the Chinese oak's lineage.

Supplementary Materials: The following are available online at http://www.mdpi.com/2223-7747/9/8/1024/s1, Figure S1: Infrageneric phylogeny of Chinese oak species inferred with (a) maximum likelihood and (b) neighbor-net methods using a concatenate chloroplast dataset. The four identified sections in the Chinese oak's lineage are color-coded. Gray circles on the branches of the maximum likelihood tree indicate bootstrap values $>60$, and a bootstrap confidence of $>60$ was shown for major clusters on the neighbor-net network; Figure S2: Infrageneric phylogeny of Chinese oak species inferred with (a) maximum likelihood and (b) neighbor-net methods based on a combined nuclear dataset. The four identified sections in the Chinese oak's lineage are color-coded. Gray circles on branches of the maximum likelihood tree indicate bootstrap values $>60$, and a bootstrap confidence of $>60$ was shown for major clusters on the neighbor-net network; Figure S3: Unrooted maximum likelihood trees based on five chloroplast alignments from the Chinese oak species. Individuals are colored according to the four identified sections in the Chinese oak's lineage; Figure S4: Unrooted maximum likelihood trees based on two nuclear loci from the Chinese oak species. Individuals are colored according to the four identified sections in the Chinese oak's lineage; Figure S5: Multiple traits-based principal component analysis (PCA) in 46 Chinese oak species; Table S1: Information of seven molecular markers used in this study; Table S2: Genetic estimation of the Chinese oak's lineage based on chloroplast and nuclear datasets; Table S3: Bonferroni $t$-test of the rates of speciation (lambda) and phenotypic evolution (beta) among four sections of the Chinese oak species; Table S4: Sample fractions of 46 Chinese oak species for a simulation of Bayesian analysis of macroevolutionary mixtures (BAMM); Table S5: Values of phenotypic traits and first two principal components (PCs) in 46 Chinese oak species.

Author Contributions: Author Contributions: Conceptualization, J.Y., Z.-L.L. and G.-F.Z.; Resource and Data Curation, J.Y., Y.-F.G., X.-D.C. and X.Z.; Formal Analysis and Validation, J.Y., M.-M.J. and G.-Q.B.; Writing, J.Y. and G.-F.Z. All authors read and approved the final manuscript.

Funding: This research is financially supported by the Projects of National Natural Science Foundation of China (31770229, 31901077), the Project funded by China Postdoctoral Science Foundation (2018M641011), the Programs of Natural Science Basic Research (2019JQ-718) and Postdoctoral Foundation from Shaanxi Province.

Acknowledgments: The authors thank Meng Xu, Zhou Tao and Feng Li for their valuable assistance in sample collections. We thank Lucia Vazquez from the University of Illinois at Springfield for modifying and proofreading the English language of this manuscript.

Conflicts of Interest: The authors declare no conflict of interest.

\section{References}

1. Lortie, C.J.; Svenning, J.C. The diversity of diversity studies: Retrospectives and future directions. Ecography 2015, 38, 330-334. [CrossRef]

2. Testo, W.L.; Sessa, E.; Barrington, D.S. The rise of the Andes promoted rapid diversification in Neotropical Phlegmariurus (Lycopodiaceae). New Phytol. 2019, 222, 604-613. [CrossRef]

3. Ricklefs, R.E. Evolutionary diversification and the origin of the diversity-environment relationship. Ecology 2006, 87, S3-S13. [CrossRef]

4. Svenning, J.C.; Borchsenius, F.; Bjorholm, S.; Balslev, H. High tropical net diversification drives the New World latitudinal gradient in palm (Arecaceae) species richness. J. Biogeogr. 2008, 35, 394-406. [CrossRef]

5. Eaton, D.A.R.; Fenster, C.B.; Hereford, J.; Huang, S.Q.; Ree, R.H. Floral diversity and community structure in Pedicularis (Orobanchaceae). Ecology 2012, 93, S182-S194. [CrossRef]

6. Donoghue, M.J. A phylogenetic perspective on the distribution of plant diversity. Proc. Natl. Acad. Sci. USA 2008, 105, 11549-11555. [CrossRef] 
7. Eaton, D.A.R.; Hipp, A.L.; González-Rodriguez, A.; Cavender-Bares, J. Historical introgression among the American live oaks and the comparative nature of tests for introgression. Evolution 2015, 69, 2587-2601. [CrossRef]

8. Ortego, J.; Noguerales, V.; Gugger, P.F.; Sork, V.L. Evolutionary and demographic history of the Californian scrub white oak species complex: An integrative approach. Mol. Ecol. 2015, 24, 6188-6208. [CrossRef]

9. Qian, H.; Wiens, J.J.; Zhang, J.; Zhang, Y.J. Evolutionary and ecological causes of species richness patterns in North American angiosperm trees. Ecography 2015, 38, 241-250. [CrossRef]

10. McVay, J.D.; Hipp, A.L.; Manos, P.S. A genetic legacy of introgression confounds phylogeny and biogeography in oaks. Proc. R. Soc. B 2017, 284, 20170300. [CrossRef]

11. Suzuki, T.; Suzuki, N.; Tojo, K. Parallel evolution of an alpine type ecomorph in a scorpionfly: Independent adaptation to high-altitude environments in multiple mountain locations. Mol. Ecol. 2019, 28, 3225-3240. [CrossRef] [PubMed]

12. Blanchard, B.D.; Moreau, C.S. Defensive traits exhibit an evolutionary trade-off and drive diversification in ants. Evolution 2017, 71, 315-328. [CrossRef] [PubMed]

13. Manos, P.S.; Doyle, J.J.; Nixon, K.C. Phylogeny, biogeography, and processes of molecular differentiation in Quercus subgenus Quercus (Fagaceae). Mol. Phylogenet. Evol. 1999, 12, 333-349. [CrossRef] [PubMed]

14. Kremer, A.; Abbott, A.G.; Carlson, J.E.; Manos, P.S.; Plomion, C.; Sisco, P.; Staton, M.E.; Ueno, S.; Vendramin, G.G. Genomics of Fagaceae. Tree Genet. Genomes 2012, 8, 583-610. [CrossRef]

15. Cavender-Bares, J. Diversity, distribution and ecosystem services of the North American oaks. Int. Oaks 2016, 27, 37-48.

16. Hipp, A.L.; Manos, P.S.; Gonzalez-Rodriguez, A.; Hahn, M.; Kaproth, M.; McVay, J.D.; Avalos, S.V.; Cavender-Bares, J. Sympatric parallel diversification of major oak clades in the Americas and the origins of Mexican species diversity. New Phytol. 2018, 217, 439-452. [CrossRef]

17. Chasse, B. Updated classification of oaks: A summary. Int. Oaks 2018, 29, 11-18.

18. Burger, W.C. The species concept in Quercus. TAXON 1975, 24, 45-50. [CrossRef]

19. Nixon, K.C. Infrageneric classification of Quercus (Fagaceae) and typification of sectional names. Ann. Sci. For. 1993, 50, 25s-34s. [CrossRef]

20. Denk, T.; Grimm, G.W. The oaks of western Eurasia: Traditional classifications and evidence from two nuclear markers. TAXON 2010, 59, 351-366. [CrossRef]

21. Simeone, M.C.; Piredda, R.; Papini, A.; Vessella, F.; Schirone, B. Application of plastid and nuclear markers to DNA barcoding of Euro-Mediterranean oaks (Quercus, Fagaceae): Problems, prospects and phylogenetic implications. Bot. J. Linn. Soc. 2013, 172, 478-499. [CrossRef]

22. Crowl, A.A.; Manos, P.S.; McVay, J.D.; Lemmon, A.R.; Lemmon, E.M.; Hipp, A.L. Uncovering the genomic signature of ancient introgression between white oak lineages (Quercus). New Phytol. 2020, 226, 1158-1170. [CrossRef] [PubMed]

23. Zhou, Z.K. Origin, phylogeny and dispersal of Quercus from China. Acta Bot. Yunnanica 1992, 14, $227-236$.

24. Pu, C.X.; Zhou, Z.K.; Luo, Y. A cladistic analysis of Quercus (Fagaceae) in China based on leaf epidermis and architecture. Acta Bot. Yunnanica 2002, 24, 689-698.

25. Deng, M.; Hipp, A.L.; Song, Y.G.; Li, Q.S.; Coombes, A.; Cotton, A. Leaf epidermal features of Quercus subgenus Cyclobalanopsis (Fagaceae) and their systematic significance. Bot. J. Linn. Soc. 2014, 176, 224-259. [CrossRef]

26. Hipp, A.L.; Manos, P.S.; Hahn, M.; Avishai, M.; Bodenes, C.; Cavender-Bares, J.; Crowl, A.A.; Deng, M.; Denk, T.; Fitz-Gibbon, S.; et al. Genomic landscape of the global oak phylogeny. New Phytol. 2020, 226, 1198-1212. [CrossRef]

27. Denk, T.; Grimm, G.W.; Manos, P.S.; Deng, M.; Hipp, A.L. An updated infrageneric classification of the oaks: Review of previous taxonomic schemes and synthesis of evolutionary patterns. In Tree Physiology. Oaks Physiological Ecology. Exploring the Functional Diversity of Genus Quercus L.; Gil-Pelegrin, E., Peguero-Pina, J.J., Sancho-Knapik, D., Eds.; Springer: Cham, Switzerland, 2017; pp. 13-38.

28. Yang, J.; Vazquez, L.; Chen, X.D.; Li, H.M.; Zhang, H.; Liu, Z.L.; Zhao, G.F. Development of chloroplast and nuclear DNA markers for Chinese oaks (Quercus subgenus Quercus) and assessment of their utility as DNA barcodes. Front. Plant Sci. 2017, 8, 816. [CrossRef]

29. Yan, M.X.; Xiong, Y.S.; Liu, R.B.; Deng, M.; Song, J.J. The application and limitation of universal chloroplast markers in discriminating East Asian evergreen oaks. Front. Plant Sci. 2018, 9, 569. [CrossRef] 
30. Zhou, Z.K. The fossil history of Quercus. Acta Bot. Yunnanica 1993, 15, 21-33.

31. Deng, M.; Jiang, X.L.; Hipp, A.L.; Manos, P.S.; Hahn, M. Phylogeny and biogeography of East Asian evergreen oaks (Quercus section Cyclobalanopsis; Fagaceae): Insights into the Cenozoic history of evergreen broad-leaved forests in subtropical Asia. Mol. Phylogenet. Evol. 2018, 119, 170-181. [CrossRef]

32. Jiang, X.L.; Hipp, A.L.; Deng, M.; Su, T.; Zhou, Z.K.; Yan, M.X. East Asian origins of European holly oaks (Quercus section Ilex Loudon) via the Tibet-Himalaya. J. Biogeogr. 2019, 46, 2203-2214. [CrossRef]

33. Xu, X.T.; Wang, Z.H.; Rahbek, C.; Lessard, J.P.; Fang, J.Y. Evolutionary history influences the effects of water-energy dynamics on oak diversity in Asia. J. Biogeogr. 2013, 40, 2146-2155. [CrossRef]

34. Zeng, Y.F.; Liao, W.J.; Petit, R.J.; Zhang, D.Y. Geographic variation in the structure of oak hybrid zones provides insights into the dynamics of speciation. Mol. Ecol. 2011, 20, 4995-5011. [CrossRef] [PubMed]

35. Zeng, Y.F.; Wang, W.T.; Liao, W.J.; Wang, H.F.; Zhang, D.Y. Multiple glacial refugia for cool-temperate deciduous trees in northern East Asia: The Mongolian oak as a case study. Mol. Ecol. 2015, 24, 5676-5691. [CrossRef] [PubMed]

36. Chen, D.M.; Zhang, X.X.; Kang, H.Z.; Sun, X.; Yin, S.; Du, H.M.; Yamanaka, N.; Gapare, W.; Wu, H.X.; Liu, C.J. Phylogeography of Quercus variabilis based on chloroplast DNA sequence in East Asia: Multiple glacial refugia and mainland-migrated island populations. PLoS ONE 2012, 7, e47268. [CrossRef]

37. Xu, J.; Deng, M.; Jiang, X.L.; Westwood, M.; Song, Y.G.; Turkington, R. Phylogeography of Quercus glauca (Fagaceae), a dominant tree of East Asian subtropical evergreen forests, based on three chloroplast DNA interspace sequences. Tree Genet. Genomes 2014, 11, 805. [CrossRef]

38. Du, F.K.; Hou, M.; Wang, W.T.; Mao, K.S.; Hampe, A. Phylogeography of Quercus aquifolioides provides novel insights into the Neogene history of a major global hotspot of plant diversity in south-west China. J. Biogeogr. 2017, 44, 294-307. [CrossRef]

39. Jiang, X.L.; Gardner, E.M.; Meng, H.H.; Deng, M.; Xu, G.B. Land bridges in the Pleistocene contributed to flora assembly on the continental islands of South China: Insights from the evolutionary history of Quercus championii. Mol. Phylogenet. Evol. 2019, 132, 36-45. [CrossRef]

40. Ju, M.M.; Feng, L.; Yang, J.; Yang, Y.C.; Chen, X.D.; Zhao, G.F. Evaluating population genetic structure and demographic history of Quercus spinosa (Fagaceae) based on specific length amplified fragment sequencing. Front. Genet. 2019, 10, 965. [CrossRef]

41. Chen, X.D.; Yang, J.; Feng, L.; Zhou, T.; Zhang, H.; Li, H.M.; Bai, G.Q.; Meng, X.; Li, Z.H.; Zhao, G.F. Phylogeography and population dynamics of an endemic oak (Quercus fabri Hance) in subtropical China revealed by molecular data and ecological niche modeling. Tree Genet. Genomes 2020, 16, 2. [CrossRef]

42. Yang, J.; Vazquez, L.; Feng, L.; Liu, Z.L.; Zhao, G.F. Climatic and soil factors shape the demographical history and genetic diversity of a deciduous oak (Quercus liaotungensis) in Northern China. Front. Plant Sci. 2018, 9, 1534. [CrossRef] [PubMed]

43. Favre, A.; Packert, M.; Pauls, S.U.; Jahnig, S.C.; Uhl, D.; Michalak, I.; Muellner-Riehl, A.N. The role of the uplift of the Qinghai-Tibetan Plateau for the evolution of Tibetan biotas. Biol. Rev. 2015, 90, 236-253. [CrossRef]

44. Zachos, J.; Pagani, M.; Sloan, I.; Thomas, E.; Billups, K. Trends, rhythms, and aberrations in global climate $65 \mathrm{Ma}$ to present. Science 2001, 292, 686-693. [CrossRef] [PubMed]

45. Simeone, M.C.; Grimm, G.W.; Papini, A.; Vessella, F.; Cardoni, S.; Tordoni, E.; Piredda, R.; Franc, A.; Denk, T. Plastome data reveal multiple geographic origins of Quercus Group Ilex. PeerJ 2016, 4, e1897. [CrossRef] [PubMed]

46. Pham, K.K.; Hipp, A.L.; Manos, P.S.; Cronn, R.C. A time and a place for everything: Phylogenetic history and geography as joint predictors of oak plastome phylogeny. Genome 2017, 60, 720-732. [CrossRef]

47. Manos, P.S.; Stanford, A.M. The historical biogeography of Fagaceae: Tracking the Tertiary history of temperate and subtropical forests of the Northern Hemisphere. Int. J. Plant Sci. 2001, 162, S77-S93. [CrossRef]

48. Hubert, F.; Grimm, G.W.; Jousselin, E.; Berry, V.; Franc, A.; Kremer, A. Multiple nuclear genes stabilize the phylogenetic backbone of the genus Quercus. Syst. Biodivers. 2014, 12, 405-423. [CrossRef]

49. Feng, L.; Zheng, Q.J.; Qian, Z.Q.; Yang, J.; Zhang, Y.P.; Li, Z.H.; Zhao, G.F. Genetic structure and evolutionary history of three alpine sclerophyllous oaks in east Himalaya-Hengduan Mountains and adjacent regions. Front. Plant Sci. 2016, 7, 1688. [CrossRef] 
50. An, M.; Deng, M.; Zheng, S.S.; Jiang, X.L.; Song, Y.G. Introgression threatens the genetic diversity of Quercus austrocochinchinensis (Fagaceae), an endangered oak: A case inferred by molecular markers. Front. Plant Sci. 2017, 8, 229. [CrossRef]

51. Cavender-Bares, J.; Gonzalez-Rodriguez, A.; Eaton, D.A.R.; Hipp, A.L.; Beulke, A.; Manos, P.S. Phylogeny and biogeography of the American live oaks (Quercus subsection Virentes): A genomic and population genetics approach. Mol. Ecol. 2015, 24, 3668-3687. [CrossRef]

52. Meng, H.H.; Su, T.; Gao, X.Y.; Li, J.; Jiang, X.L.; Sun, H.; Zhou, Z.K. Warm-cold colonization: Response of oaks to uplift of the Himalaya-Hengduan Mountains. Mol. Ecol. 2017, 26, 3276-3294. [CrossRef] [PubMed]

53. Liu, J.Q.; Duan, Y.W.; Hao, G.; Ge, X.J.; Sun, H. Evolutionary history and underlying adaptation of alpine plants on the Qinghai-Tibet Plateau. J. Syst. Evol. 2014, 52, 241-249. [CrossRef]

54. Renner, S.S. Available data point to a 4-km-high Tibetan Plateau by $40 \mathrm{Ma}$, but 100 molecular-clock papers have linked supposed recent uplift to young node ages. J. Biogeogr. 2016, 43, 1479-1487. [CrossRef]

55. Su, T.; Spicer, R.A.; Li, S.H.; Xu, H.; Huang, J.; Sherlock, S.; Huang, Y.J.; Li, S.F.; Wang, L.; Jia, L.B.; et al. Uplift, climate and biotic changes at the Eocene-Oligocene transition in south-eastern Tibet. Natl. Sci. Rev. 2019, 6, 495-504. [CrossRef]

56. Simeone, M.C.; Cardoni, S.; Piredda, R.; Imperatori, F.; Avishai, M.; Grimm, G.W.; Denk, T. Comparative systematics and phylogeography of Quercus Section Cerris in western Eurasia: Inferences from plastid and nuclear DNA variation. PeerJ 2018, 6, e5793. [CrossRef]

57. Cavender-Bares, J.; Kothari, S.; Meireles, J.E.; Kaproth, M.A.; Manos, P.S.; Hipp, A.L. The role of diversification in community assembly of the oaks (Quercus L.) across the continental U.S. Am. J. Bot. 2018, 105, 565-586. [CrossRef]

58. Leroy, T.; Louvet, J.M.; Lalanne, C.; Provost, G.L.; Labadie, K.; Aury, J.M.; Delzon, S.; Plomion, C.; Kremer, A. Adaptive introgression as a driver of local adaptation to climate in European white oaks. New Phytol. 2020, 226, 1171-1182. [CrossRef]

59. Rabosky, D.L.; Adams, D.C. Rates of morphological evolution are correlated with species richness in salamanders. Evolution 2012, 66, 1807-1818. [CrossRef]

60. Moore, B.R.; Donoghue, M.J. Correlates of diversification in the plant clade Dipsacales: Geographic movement and evolutionary innovations. Am. Nat. 2007, 170, S28-S35. [CrossRef]

61. Wellenreuther, M.; Merot, C.; Berdan, E.; Bernatchez, L. Going beyond SNPs: The role of structural genomic variants in adaptive evolution and species diversification. Mol. Ecol. 2019, 28, 1203-1209. [CrossRef]

62. Nagamitsu, T.; Uchiyama, K.; Izuno, A.; Shimizu, H.; Nakanishi, A. Environment-dependent introgression from Quercus dentata to a coastal ecotype of Quercus mongolica var. crispula in northern Japan. New Phytol. 2020, 226, 1018-1028. [CrossRef] [PubMed]

63. Koehler, K.; Center, A.; Cavender-Bares, J. Evidence for a freezing tolerance-growth rate trade-off in the live oaks (Quercus series Virentes) across the tropical-temperate divide. New Phytol. 2012, 193, 730-744. [CrossRef]

64. Cannon, C.H.; Petit, R.J. The oak syngameon: More than the sum of its parts. New Phytol. 2020, 226, 978-983. [CrossRef] [PubMed]

65. Yang, J.; Di, X.Y.; Meng, X.; Feng, L.; Liu, Z.L.; Zhao, G.F. Phylogeography and evolution of two closely related oak species (Quercus) from north and northeast China. Tree Genet. Genomes 2016, 12, 89. [CrossRef]

66. Hall, T.A. BioEdit: A user-friendly biological sequence alignment editor and analysis program for Windows 95/98/NT. Nucleic Acids Symp. Ser. 1999, 41, 95-98.

67. Li, H.P. A new test for detecting recent positive selection that is free from the confounding impacts of demography. Mol. Biol. Evol. 2011, 28, 365-375. [CrossRef]

68. Rozas, J.; Sanchez-Delbarrio, J.C.; Messeguer, X.; Rozas, R. DnaSP, DNA polymorphism analyses by the coalescent and other methods. Bioinformatics 2003, 19, 2496-2497. [CrossRef]

69. Minh, B.Q.; Nguyen, M.A.T.; von Haeseler, A. Ultrafast approximation for phylogenetic bootstrap. Mol. Biol. Evol. 2013, 30, 1188-1195. [CrossRef]

70. Nguyen, L.T.; Schmidt, H.A.; Von Haeseler, A.; Minh, B.Q. IQ-TREE: A fast and effective stochastic algorithm for estimating maximum-likelihood phylogenies. Mol. Biol. Evol. 2014, 32, 268-274. [CrossRef]

71. Letunic, I.; Bork, P. Interactive Tree Of Life (iTOL) V4: Recent updates and new developments. Nucleic Acids Res. 2019, 47, W256-W259. [CrossRef]

72. Bryant, D.; Moulton, V. Neighbor-Net: An agglomerative method for the construction of phylogenetic networks. Mol. Biol. Evol. 2004, 21, 255-265. [CrossRef] 
73. Suchard, M.A.; Lemey, P.; Baele, G.; Ayres, D.L.; Drummond, A.J.; Rambaut, A. Bayesian phylogenetic and phylodynamic data integration using BEAST 1.10. Virus Evol. 2018, 4, vey016. [CrossRef] [PubMed]

74. Zhou, Z.K. Fossils of the Fagaceae and their implications in systematics and biogeography. Acta Phytotaxon. Sin. 1999, 37, 369-385.

75. Rabosky, D.L. Automatic detection of key innovations, rate shifts, and diversity-dependence on phylogenetic trees. PLoS ONE 2014, 9, e89543. [CrossRef] [PubMed]

76. Rabosky, D.L.; Grundler, M.; Anderson, C.; Title, P.; Shi, J.J.; Brown, J.W.; Huang, H.T.; Larson, J.G. BAMMtools: An R package for the analysis of evolutionary dynamics on phylogenetic trees. Methods Ecol. Evol. 2014, 5, 701-707. [CrossRef]

77. R Core Team. R: A Language and Environment for Statistical Computing; R Foundation for Statistical Computing: Vienna, Austria, 2011.

(C) 2020 by the authors. Licensee MDPI, Basel, Switzerland. This article is an open access article distributed under the terms and conditions of the Creative Commons Attribution (CC BY) license (http://creativecommons.org/licenses/by/4.0/). 